\title{
METODOLOGIA ATIVA NA EDUCAÇÃO A DISTÂNCIA: SUA APLICAÇÃO NAS AULAS PRÁTICAS DO CURSO DE ENGENHARIA DE PRODUÇÃO.
}

\author{
LONDRINA/PR MAIO/2018
}

\author{
lolanda Claudia Sanches Catarino - UNOPAR - iolanda.catarino@unopar.br \\ Jenai Oliveira Cazetta - UNOPAR - jenai.ocazetta@unopar.br \\ Cristiane Regina Yamaguti Mashuda - UNOPAR - cristiane.mashuda@unopar.br \\ Marcio Ronald Sella - UNOPAR - marcio.sella@kroton.com.br \\ Melina Klaus - UNOPAR - melina@unopar.br
}

Tipo: Relato de Experiência Inovadora (EI)

Categoria: Métodos e Tecnologias

Setor Educacional: EDUCAÇÃO SUPERIOR

\begin{abstract}
RESUMO
Nos dias de hoje, o ensino superior visa fundamentalmente a preparação para o exercício da cidadania e a formação integral do egresso, cabendo aos cursos de graduação o preparo para a vida profissional a partir de uma aprendizagem significativa, na qual sejam consideradas as experiências, os interesses e as necessidades dos alunos e das demandas do mercado de trabalho, em consonância com as políticas públicas e as diretrizes de órgãos regulatórios. Um dos grandes desafios das atividades pedagógicas práticas no ensino superior, em especial nos cursos de engenharias da modalidade a distância, é a superação das metodologias tradicionais de ensino para engajar os alunos no papel de agentes ativos na construção do seu conhecimento e criatividade. A integração das tecnologias digitais de informação e comunicação com as metodologias ativas de aprendizagem proporcionam o compartilhamento de experiências entre os alunos e educadores de forma dinâmica, proativa e colaborativa. Diante deste cenário, o objetivo deste artigo é apresentar o modelo adotado para realizar as aulas práticas do curso de graduação de Engenharia de Produção da UNOPAR, da modalidade de ensino a distância, que adota a abordagem pedagógica do Blended Learning, em específico, a proposta metodológica da sala de aula invertida, no modelo acadêmico da Instituição. Para o desenvolvimento deste estudo adotou-se a pesquisa descritiva a partir de um levantamento bibliográfico, com abordagem do problema qualitativa. Utilizou-se como procedimento, um estudo de caso do curso de Engenharia de Produção, apresentando o modelo de prática pedagógica adotado nas aulas das disciplinas com conteúdos práticos e de laboratórios, e a sua aplicação em uma aula da disciplina de Física Geral e Experimental: Mecânica, do terceiro semestre do Curso.
\end{abstract}

Palavras-chave: Metodologia Ativa, Blended Learning, Sala de Aula Invertida, Educação Superior, Engenharia, Aula Prática.

\section{AGRADECIMENTOS}

\author{
UNIVERSIDADE PÍTAGORAS UNOPAR E \\ KROTON EDUCACIONAL
}




\section{INTRODUÇÃO}

Um dos maiores desafios na Educação a Distância (EAD), segundo Moran (2013, p. 5) é "estimular os alunos a serem pesquisadores e não meramente executores de tarefas, que se sintam motivados para investigar, para irem além do senso comum, que explorem todo o potencial que as redes tecnológicas e humanas nos possibilitam". Em consonância com este desafio, as metodologias ativas de aprendizagem enfatizam a importância da interação dos alunos no processo de ensino e aprendizagem com o auxílio das Tecnologias da Informação e Comunicação (TICs), a partir de práticas pedagógicas que conduzam a reflexão, análise, síntese, colaboração, avaliação, resolução de problemas e o desenvolvimento de projetos.

$\mathrm{Na}$ literatura científica, as pesquisas mostram que as metodologias ativas são estratégias de ensino que potencializam a aprendizagem de forma significativa. Os alunos que vivenciam esse método adquirem mais confiança em suas decisões e na aplicação do conhecimento em situações práticas, aprendendo a se expressarem melhor oralmente e por escrito, bem como, desenvolvendo habilidades para resolverem problemas e a tomarem decisões, reforçando a autonomia no pensar e no atuar (RIBEIRO, 2005).

Diante do amplo espectro da diversidade educacional brasileira, a EAD atualmente assume desafios importantes para melhorar a qualidade do ensino e oferecer propostas pedagógicas mais inovadores, fundamentadas nas metodologias ativas de aprendizagem e apoiadas pelas TICs. Nesse contexto, os cursos de graduação, da modalidade $E A D$, das diferentes áreas de conhecimento que têm conteúdos com atividades práticas e de laboratórios, instituídos pelas respectivas Diretrizes Curriculares Nacionais (DCNs), precisam contemplar em seu Projeto Pedagógico de Curso (PPC) o modelo que é adotado para conduzir as aulas práticas dos cursos.

O objetivo deste artigo é apresentar o relato da experiência com o modelo adotado para realizar as aulas práticas dos cursos de engenharia da UNOPAR, da modalidade EAD, que adota a abordagem pedagógica do Blended Learning, em específico, a proposta metodológica da sala de aula invertida. Com o intuito de refletir sobre à aplicação desse modelo, este estudo visa também apresentar uma aula prática do curso de Engenharia de Produção realizada, no Laboratório Multidisciplinar, para consistir e validar o modelo proposto pela Instituição.

Todas as ações dos cursos de graduação de engenharia da UNOPAR ocorrem para quebrar o paradigma do ensino tradicional, centrado no professor em que o aluno 
recebe passivamente o conteúdo, e consolidar um modelo dialógico, em que professor e aluno interajam no processo de ensino e aprendizagem, por meio de diferentes estratégias, canais e procedimentos, com o intuito de que a aprendizagem se torne significativa, ou seja, que dialogue com a realidade do estudante (UNOPAR, 2017).

\section{REFERENCIAL TEÓRICO}

Esta seção apresenta uma breve revisão da literatura para fundamentar a proposta deste trabalho.

\subsection{Metodologias Ativas}

Ao logo dos anos, diversas propostas metodológicas têm surgido, sendo uma delas as metodologias ativas. Bastos (2006) define metodologias ativas como processos interativos de conhecimento, análise, estudos, pesquisas e decisões individuais ou coletivas, com a finalidade de encontrar soluções para um problema, sendo que o professor atua como facilitador ou orientador para atingir um objetivo. Na concepção de Prince (2004), a abordagem da aprendizagem ativa contempla um conjunto de práticas pedagógicas que exige do estudante o papel de protagonista, criando oportunidades na construção do seu conhecimento, em oposição à aprendizagem passiva.

Paulo Freire (2011) defendeu as metodologias ativas afirmando que na educação de adultos, o que impulsionava a aprendizagem era a resolução de problemas, a superação de desafios, a construção do conhecimento a partir de experiências vividas pelos próprios alunos.

Com o intuito de tornar o aluno comprometido, motivado e participante do seu processo de aprendizado, é que as instituições de educação básica e educação superior estão adotando em seus modelos de ensino as metodologias ativas. Estas em sintonia com as intensas mudanças das TICs, estão oportunizando a integração dos espaços e tempos e a formação crítica, reflexiva e criativa de profissionais que se adaptem as constantes mudanças da sociedade contemporânea.

A integração das TICs nas atividades de sala de aula fez surgir o conceito de Blended Learning ou ensino híbrido, impulsionado o modelo de sala de aula invertida (flipped classroon) como uma das estratégias de metodologia ativa de aprendizagem. Stake e Horn (2012) defendem o Blended Learning como um processo de educação formal que mescla momentos presencias e online, havendo a interação entre professores e alunos. Nas atividades online, o aluno possui o controle de onde, como e com quem vai estudar. 
As atividades presencias devem contar com o apoio do professor e tutores para valorizarem a interação interpessoal e mediarem as atividades online.

A sala de aula invertida é o método atual adotado nos cursos de graduação de Engenharia da UNOPAR. Neste modelo, os conteúdos são previamente disponibilizados para estudo no Ambiente Virtual de Aprendizagem (AVA) antes que ocorra a aula. A aula passa a ser um momento de discussão dos conteúdos já estudados, com a realização de atividades práticas, como por exemplo, a resolução de problemas e projetos, atividades em grupo e práticas em laboratório. Desta maneira, inverte-se o modelo tradicional de aprendizagem, tornando a aula um lugar de aprendizagem ativa, onde o professor trabalha as dificuldades dos alunos, ao invés de apenas apresentar o conteúdo da disciplina.

\subsection{Aulas Práticas da EAD - Modelo KLS 2.0}

A UNOPAR implantou nos cursos de graduação o modelo acadêmico KLS 2.0 que adota a abordagem Blended Learning com a proposta metodológica da sala de aula invertida. A metodologia de ensino do modelo KLS envolve a resolução de situação-problema vinculada à uma situação próxima à realidade profissional. A aula modelo, baseada no conceito de sala de aula invertida, compreende três momentos didáticos, a saber (UNOPAR, 2017): 1 - Pré-aula, momento que antecede a aula e que tem por objetivos desafiar, incentivar e estimular o aluno para a aprendizagem, por meio de proposições via Web Aula, Livro Didático, objetos de aprendizagem, textos ou outros recursos que o professor julgar relevantes; 2 - Aula mediada (teleaula), momento em que são desenvolvidas atividades para resolverem situações-problema e em que as trocas de experiências e conhecimentos são estimuladas; e 3 - Pós-aula, momento destinado à realização de atividades e de propor novos desafios a fim de despertar os alunos para novas aprendizagens.

Seguindo os três momentos didáticos de uma aula modelo, os cursos da EAD da Instituição que têm disciplinas com carga horária prática estruturam suas aulas práticas, conforme é ilustrado na Figura 1 a seguir: 
A Figura 1 - Estrutura da Aula Modelo Prática da EAD.

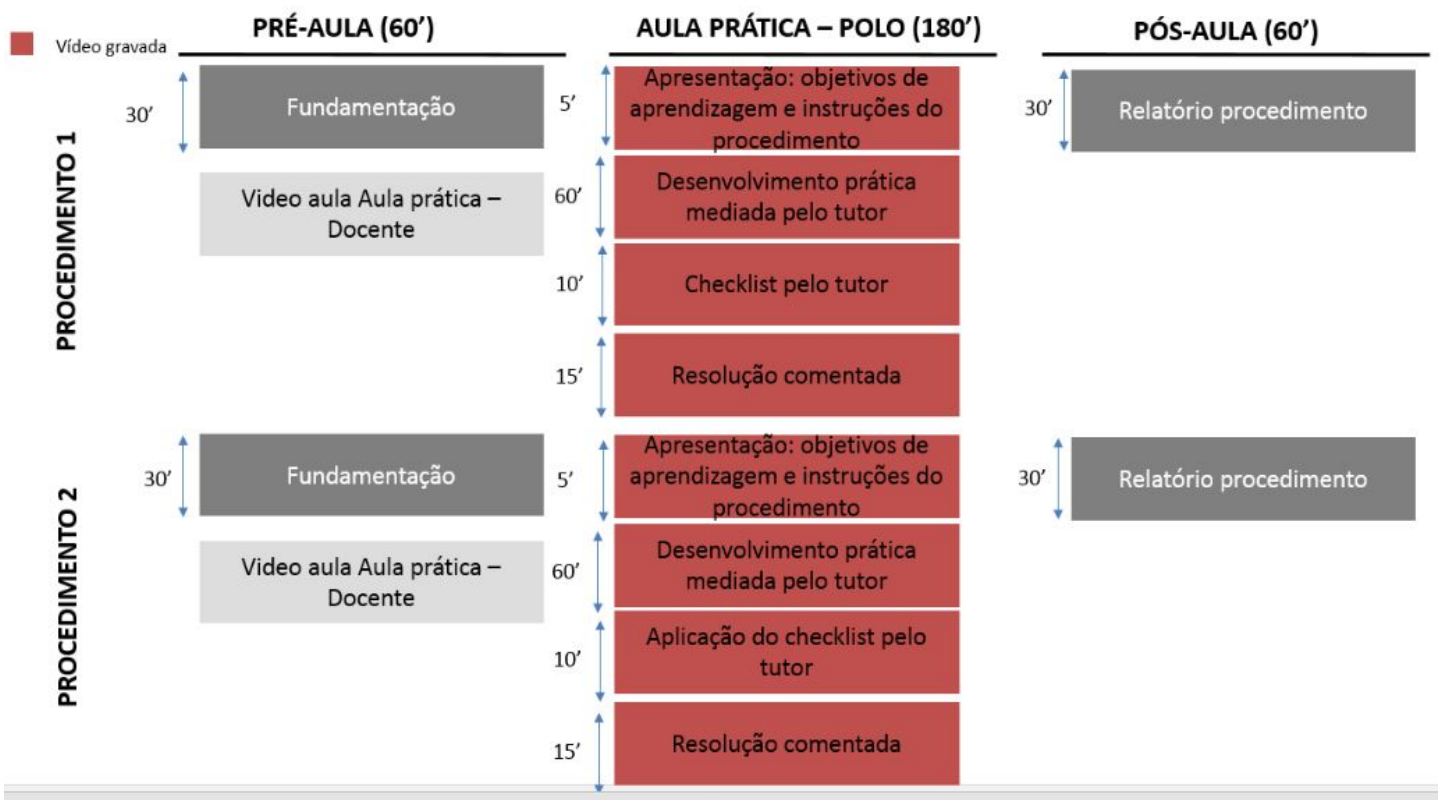

Fonte: UNOPAR (2017).

A aula prática envolve, geralmente, dois procedimentos, de 90 minutos cada, exceto em casos bem particulares, onde o desenvolvimento de um procedimento é mais demorado. As aulas práticas precisam ser agendadas pelos polos e são registradas diretamente no sistema de informação Institucional. O polo precisa acordar com toda a turma um horário, por meio do "Termo de Consentimento para Horário das Aulas Práticas", em um dia diferente do dia e hora da Aula Teórica (teleaula), preferencialmente no horário noturno. Há um controle de frequência, bem como o preenchimento de uma ficha de avaliação para cada aula prática realizada. Os tutores, bem como os alunos, podem interagir com o professor responsável através de um fórum.

$\mathrm{Na}$ aula prática, os alunos trabalham os conteúdos apresentados no Livro Didático e na Web Aula, via atividades mediadas de aprendizagem. Este tempo didático e? dividido em três etapas: 1. Pensando a Aula; 2. Orientando Atividades da Aula Atual; 3. Avaliação. Estas atividades devem ser alinhadas e combinadas considerando o desenvolvimento das competências e os objetivos de aprendizagem.

Para cada unidade do Livro Didático, há quatro roteiros a serem seguidos, abrangendo: título da unidade curricular (disciplina), palavras-chave, competência de fundamentos de área, conteúdo, objetivos de aprendizagem, materiais utilizados, softwares (utilização ou não), equipamentos de proteção individual, aula prática, procedimentos e observações.

A dinâmica das aulas práticas é dividida em 3 partes. O primeiro momento envolve a 
contextualização e a apresentação do experimento. Nesta fase é mostrada a relação entre a teoria e a prática que será apresentada, sempre com ênfase na abordagem de situações cotidianas (exemplos de máquinas, sistemas etc). $\mathrm{Na}$ apresentação do experimento são descritos os objetivos que devem ser alcançados e são apresentados os materiais que serão utilizados, mostrando cada instrumento, sua utilidade, suas características e suas especificidades. Nesta fase também são discutidos os procedimentos, relativos à segurança, que devem ser observados ao se utilizar o laboratório, tais como, trajes, sapatos e postura dentro do mesmo.

A segunda parte envolve a montagem do experimento com o objetivo de oferecer um guia para o aluno e para o tutor presencial que está no polo de apoio. São esclarecidos os procedimentos que devem ser utilizados na coleta de dados, bem como a construção de tabelas para facilitar a manipulação desses dados, enfatizando a necessidade dos resultados serem anotados de forma organizada. Nesta fase ocorre a realização do experimento, com explicação detalhada de cada uma de suas partes.

A terceira parte é o momento em que os dados experimentais são confrontados com a teoria. Um momento importante nesta fase é a discussão dos erros envolvidos no processo de coleta de dados, como, também, da propagação desses erros nas quantidades a serem calculadas. É importante lembrar que erros são inerentes ao processo de medição, não podendo, em muitos casos, serem evitados, mas podem ser estimados.

\section{PROCEDIMENTOS METODOLÓGICOS}

Para o desenvolvimento do estudo adotou-se a seguinte tipologia de pesquisa. Quanto aos objetivos trata-se de pesquisa descritiva a partir de um levantamento bibliográfico nas fontes primárias clássicas e emergentes e em publicações nacionais e internacionais das bases de dados Web of Science e Scielo, com abordagem do problema qualitativa. Utilizou-se como procedimento um estudo de caso do curso de Engenharia de Produção, modalidade EAD, referente a disciplina de Física Geral e Experimental: Mecânica, do 3ª semestre do curso. O curso de Engenharia de Produção tem carga horária total de 3.920 horas, sendo que 3.500 horas correspondentes às disciplinas teóricas e práticas.

Considerando a atual matriz curricular do Curso, as disciplinas com carga horária prática são realizadas nos seguintes semestres: $2^{\circ}$ Semestre - disciplina: Química Geral e Experimental; 3o Semestre: disciplinas: Física Geral e Experimental: Mecânica; Algoritmos e Lógica de Programação; e Ciência Dos Materiais; 4 Semestre: disciplinas: 
Desenho Técnico; Física Geral e Experimental: Energia; e Desenho Auxiliado por Computador; 5ํㅗㄹ Semestre: disciplinas: Fenômenos de Transporte; e Resistência dos Materiais; 6o Semestre: disciplinas: Ergonomia; e Metrologia e Controle Geométrico; 8ํㅡㄴ Semestre: disciplinas: Controle e Automação de Processos Industriais; e Pesquisa Operacional: Programação Matemática; 9 Semestre: disciplina: Pesquisa Operacional: Simulação; e 10 Semestre: disciplina: Projeto de Fábrica e Instalações Industriais.

Foram utilizadas como técnicas de coleta de dados intensiva, a realização de entrevistas com o corpo docente que ministram disciplinas com carga horária prática e com os tutores presenciais dos polos que acompanharam as atividades dos alunos em alguns polos de oferta do Curso em 2017, e como técnica extensiva, a análise documental da ficha de avaliação das aulas práticas da disciplina de Física Geral e Experimental: Mecânica.

\section{ESTUDO DE CASO}

A seguir é apresentado uma aula prática (As Condições de Equilíbrio de um Móvel em um Plano Inclinado) da Unidade 2 da disciplina de Física Geral e Experimental: Mecânica, do $3^{\underline{a}}$ semestre do curso de Engenharia de Produção. As aulas práticas desta disciplina são realizadas no laboratório multidisciplinar dos polos de apoio presencial para grupos de 15 alunos, mediante assinatura dos alunos no "Termo de Consentimento para Horário das Aulas Práticas". Para cada aula prática, o técnico responsável pelo laboratório organiza os materiais que serão utilizados na aula, conforme orientação prévia do professor da disciplina e do roteiro da mesma. O roteiro desta aula descrito no Livro Didático da disciplina, abrange:

a. Título da Unidade Curricular: Física Geral e Experimental: Mecânica;

b. Palavras-chave: Primeira lei de Newton; equilíbrio; repouso; forças;

c. Competência de Fundamentos de Área: Conhecer a teoria e aplicar, por meio da experimentação realizada por observação e análise dos fenômenos físicos, os principais conceitos referentes à cinemática, à dinâmica, ao trabalho e energia $e$ ao momento linear, impulso e colisões;

d. Conteúdo: dinâmica - Leis de Newton do Movimento e suas Aplicações: Uso da Primeira Lei de Newton;

e. Objetivos de Aprendizagem: Reconhecer as forças que atuam em um objeto: peso, normal, atrito, tensão, força elástica; Analisar as componentes da força peso em um plano inclinado; Determinar a dependência dos componentes da força peso em função do ângulo de inclinação do plano;

f. Materiais Utilizados: Plano inclinado com ajuste angular regulável (escala de 0 a 
$45^{\circ}$, sistema de elevação contínuo, sapatas niveladoras, escala na lateral do trilho secundário) - quantidade 3 ; massas acopláveis de $50 \mathrm{~g}$ - quantidade 6 ; carrinho - quantidade 3; dinamômetro de $2 \mathrm{~N}$ - quantidade 3;

g. Softwares: não aplicável;

h. Equipamentos de Proteção Individual (EPI): Durante as atividades de laboratório, o professor, o aluno e os técnicos devem sempre usar vestimenta adequada para que as atividades não ofereçam risco à segurança e à saúde.

Iniciou-se a aula modelo, a partir da realização da "Pré-Aula" de 60 minutos, ministrada pelo professor da disciplina via vídeo aula. Nesta, apresentou-se a fundamentação do conteúdo exposto no Livro Didático e na Web Aula e a demonstração das atividades práticas mediadas de aprendizagem.

A realização da "Aula Prática - Polo" totalizou 180 minutos com a mediação do tutor presencial e na presença do Técnico de Laboratório. Esta aula prática foi baseada no roteiro n․ 1032.043 do Livro de Atividades Experimentais - Física Experimental Mecânica - Plano Inclinado - EQ001F - Cidepe. Contemplou os seguintes passos:

1. Utilizando o dinamômetro, determine o peso $P$ no móvel formado pelo conjunto carro mais as 2 massas de $50 \mathrm{~g}$ acopladas. Anote o resultado;

2. Monte o plano inclinado com o móvel, prendendo a cabeceira do dinamômetro entre os dois fixadores, de forma que fique paralelo à rampa, conforme ilustra a Figura 2 a seguir;

3. Incline a rampa até o ângulo desejado (não utilizar $30^{\circ}$ ), girando o manípulo. Anote o ângulo;

4. Verifique o "zero" no dinamômetro;

5. Prenda o móvel pela conexão flexível do dinamômetro;

6. Peça para o aluno esquematizar o diagrama de corpo livre do móvel;

7. Se desconectar o móvel do dinamômetro, o que acontecerá? Justifique;

8. Agora, devagar, com cuidado e segurando com a mão a cabeceira do plano inclinado, aumente a inclinação até 90;

9. Com base no diagrama de corpo livre esquematizado para a primeira inclinação do plano: a) Peça para o aluno projetar e calcular as componentes da força peso; Peça para o aluno calcular a força de tensão aplicada pelo dinamômetro no móvel; e Peça para o aluno calcular a força normal;

10. Solicite aos alunos que avaliem para quais valores tendem as projeções da força peso quando o plano está inclinado de $90^{\circ}$;

11. Utilizando agora uma inclinação de $30^{\circ}$, peça para os alunos desenharem um novo diagrama de corpo livre e calcularem a força que o dinamômetro deve 
indicar para que o móvel continue em equilíbrio. Após os cálculos, solicite que eles verifiquem, experimentalmente, o resultado obtido;

12. Se o professor achar conveniente, pode repetir o item 12 sugerindo outro ângulo, ainda não utilizado, aos alunos.

Figura 2 - Plano Inclinado com o Dinamômetro.

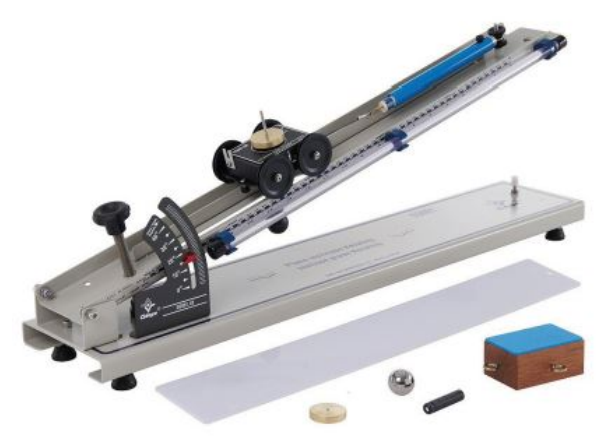

Fonte: Livro de Atividades Experimentais - Física Experimental - Mecânica - Plano Inclinado - EQ001F - Cidepe.

Finalizou a aula modelo com a "Pós-Aula" de 60 minutos, a partir da realização da atividade avaliativa individual, o relatório procedimento, conduzida pelo tutor presencial, o qual foi descrito o feedback do experimento.

A partir da análise dos dados sobre a entrevista com a professora responsável pela disciplina apresentada e com alguns tutores presenciais dos polos que acompanharam 0 experimento da aula ministrada em 2017, observou que a estrutura da aula modelo para a realização de conteúdos práticos em laboratório é satisfatória e favorável para promover a articulação das práticas pedagógicas de forma ativa e interativa, potencializando a motivação, reflexão, análise e a construção do conhecimento dos alunos. Considerando os relatórios procedimentais realizados pelos alunos das turmas envolvidas no estudo, também foi possível constatar que os alunos tiveram mais facilidade para refletirem sobre os resultados obtidos com o experimento e discutirem os erros cometidos, com isso conseguiram demonstrar se os objetivos da experiência foram alcançados.

\section{CONSIDERAÇÕES FINAIS}

$\mathrm{Na}$ educação presencial e a distância cresce a importância das metodologias ativas adotadas nos modelos de ensino com o auxílio das TICs. O Blended Learning, $b$ learning ou ensino híbrido tornou-se uma tendência na $E A D$, mesclando aulas online 
com aulas presenciais, proporcionando assim, maior flexibilidade ao processo de ensino e aprendizagem.

Um dos grandes desafios das atividades pedagógicas práticas na educação superior, em especial nos cursos de engenharias da modalidade de ensino a distância, é a superação das metodologias tradicionais de ensino para engajar os alunos no papel de agentes ativos na construção do seu conhecimento e criatividade. A integração das tecnologias digitais de informação e comunicação com as metodologias ativas de aprendizagem proporcionam o compartilhamento de experiências entre os alunos e educadores de forma dinâmica, proativa e colaborativa.

\section{REFERÊNCIAS:}

BASTOS, C. C. Metodologias Ativas. 2006. Disponível em: http://educacaomedicinablogspot.com.br/2006/02/metodologias-ativas.html. Acesso em: 17 abril 2018.

FREIRE, P. Pedagogia do oprimido. 50․․ ed. Rio de Janeiro: Paz e Terra, 2011.

MORAN, José Manuel. A educação a distância, mais focada em pesquisa e colaboração. In: FIDALGO, Fernando (Org.). Educação a Distância: meios, atores e processos. Belo Horizonte: CAED-UFMG, 2013, p. 39-51. Disponível em: http://www.eca .usp.br/prof/moran/site/textos/educacao_online/pesquisa_e_colaboracao.pdf. Acesso em: 15 fev 2018.

PRINCE, M. Does active learning work? A review of the research. Journal Engineering Education, v. 93, p. 223-231, Jul 2004.

RIBEIRO, R. C. A aprendizagem baseada em problemas (PBL): uma implementação na educação em Engenharia, Tese de Doutorado, Universidade Federal de São Carlos, São Paulo, 2005.

STAKER, H.; HORN, M. B. Classifying K-12 blended learning. Mountain View, CA: Innosight Institute, Inc. 2012. Disponi?vel em: . Acesso em: 10 mar. 2018.

UNOPAR. Projeto Pedagógico do Curso de Engenharia de Produção. Educação a Distância. Londrina: Universidade Pitágoras UNOPAR, 2017. 